DOI: $10.15503 /$ jecs20141-99-109

\title{
EXPERIENTIAL EDUCATION AGAINST ENVIRONMENTAL DENIAL IN ENVIRONMENTAL ETHICS EDUCATION: A CASE STUDY
}

\author{
TOMAŽ GRUŠOVNIK \\ Faculty of Education, University of Primorska \\ (Cankarjeva 5, Koper, Slovenia) \\ e-mail: tomaz.grusovnik@zrs.upr.si \\ ANA ARZENŠEK \\ Faculty of Management, University of Primorska, \\ (Cankarjeva 5, Koper, Slovenia) \\ e-mail: ana.arzensek@fm-kp.si
}

@) $\odot \Theta \Theta$

\begin{abstract}
Recent research shows that 'environmental denial' (the denial of anthropogenic impact on the natural world) plays an important role in environmental education. The difficulty in changing our detrimental habits stems from the fact that identities in our societies are bound up with consumerist practices. Because we cannot simply give up practices that shape our identity, environmental education has to find ways of substituting unhealthy habits with environmentally acceptable ones. One method of achieving this is through experiential education based on experiences with the natural world and their importance for identity formation. The paper presents a case study involving experiential education in environmental ethics, implemented at the university level. Findings show that the implementation of experiential education technique (field trip) yielded positive results in connection with students' overcoming of environmental denial and consequential change of their environmental outlook.
\end{abstract}

Key words: experiential education, environmental education, environmental denial

\section{INTRODUCTION}

In his A Sand County Almanac (1949) Aldo Leopold wrote that "We can be ethical only in relation to something we can see, feel, understand, love, or otherwise have faith in" (p. 214). A. Leopold's idea bears close resemblance to Richard Rorty's views on ethics and moral development, which represent the philosophical background of this paper and which emphasize the role of moral sentiment, drawing from Hume's philosophy, in which "moral distinctions are not derived from reason". R. Rorty (1999) claims that in such ethics - juxtaposed to ethics that derives its justification from reason in the form of the Kantian categorical imperative and rational moral obligation - "Moral development in the individual, and moral progress in the 
human species as a whole, is a matter of re-making human selves so as to enlarge the variety of relationships which constitute those selves" (p. 79). Closely resembling John Dewey's idea of education as growth (cf. Dewey, 1963, p. 36), such ethical philosophy rests upon the conviction that sentiments matter most in ethics and that there is no objective, natural cut between morality and prudence that is discoverable by reason. Thus, according to R. Rorty (1998), our emphasis should be on sentimental education, as "most of the work of changing moral institutions is being done by manipulating our feelings rather than by increasing our knowledge" (p. 172).

The pragmatist idea that ethics is not a (purely, or even essentially) rational enterprise, and the fact that humans are prone to disregard obvious facts when it comes to modifying their behaviour (environmental denial), joined with insight into the importance of experience for both human identity as well as education, make us raise doubts about the efficiency of classical methods of teaching environmental and animal ethics in university courses, relying mostly on reading relevant textual material. This does not mean that one should give up reading books and analyzing arguments, but it does suggest that narrative subject-matter should necessarily be complemented and upgraded with experiential educational methods, relying on the prima facie experience of students.

Because of this firm conviction, an attempt was made at the Department of Philosophy of the University of Primorska (Koper, Slovenia) to enrich the educational process with experiential educational methods: students participating in the course Ethics and the Knowledge-Based Society were taken to a landfill where they experienced dilemmas in waste management and examined some consequences of our lifestyles. The results of this field trip were quite interesting and inspiring as they clearly opened up more space for moral reflection and action, as the last chapter tries to show. However, before turning to this more practical part of the research, we first examine mechanisms of what seems to be one of the most difficult obstacles in environmental education. This analysis will pave the way towards a promising method for successfully overcoming environmental denial.

\section{ENVIRONMENTAL DENIAL}

Contemporary efforts to change public opinion about environmental issues seem to be facing an obstacle in the form of disbelief and amotivation. The phenomenon recently attracted the attention of natural scientists as well as psychologists: the psychologist Allen Newell and the climate scientist Andrew Pitman conclude their recent paper The Psychology of Global Warming (2010) with the observation that "simply presenting the facts and figures about global warming has failed to convince large portions of the general public, journalists, and policy makers about the scale of the problem and the urgency of required action" (p. 1012). Thus the shift in attention in the environmental sciences from data gathering to education and motivation psychology applied to environmental issues, and to an examination of the conditions and circumstances under which social change is likely to occur, is hardly surprising.

Recently, Pascal Diethelm and Martin McKee noted a connection between the refusal to acknowledge the effects of man-made $\mathrm{CO}_{2}$ emissions on climate change 
and the refusal to acknowledge the occurrence of gruesome war events, such as the Holocaust (2009, p. 2). They state a whole range of peculiar phenomena, from denial that HIV causes AIDS, to denial that smoking causes cancer, as well as the aforementioned two, as special cases exhibiting the general trait of denialism. Drawing from the Hoofnagle brothers, P. Diethelm and M. McKee define denialism as: "The employment of rhetorical arguments to give the appearance of legitimate debate where there is none, an approach that has the ultimate goal of rejecting a proposition on which a scientific consensus exists" (2009, p. 2).However, what P. Diethelm and M. McKee research does not take into consideration is the fact that it is not just a few people with special interests who deny the existence of climate change and the degradation of our environment. Their line of thought seems to presuppose that denialists are individuals who manipulate scientific data and employ rhetorical figures in order to confuse the public about otherwise well-established truths and further their own interests. P. Diethelm and M. McKee (2009) research does not account for the fact that a large portion of the public seems to wholeheartedly support the denialists. It is precisely this fact that seems the oddest and the most intricate: Why are we more prone to listen to denialists than to the majority of scientists?

In the text System Justification, the Denial of Global Warming, and the Possibility of "System-Sanctioned Change" Irina Feygina, John T. Jost and Rachel E. Goldsmith (2009) seek to answer this question. They argue that "overcoming the apathy, denial, and resistance among people who are faced with evidence of environmental problems is imperative if we are ever to increase public willingness to act in ways that help rather than harm the environment" (p. 1). What stands in the way of "attitudinal and behavioral change" is, for them, a "relatively widespread tendency to rationalize 'the way things are' and, in so doing, deny environmental problems" (p. 2). More precisely, for I. Feygina, J. T. Jost and R. E. Goldsmith (2009), environmental denial, which is seen as a "powerful barrier to environmentalism," stems from the perceived incompatibility between "taking care of the natural world," on one hand, and "upholding current social and economic practices and institutions," on the other, which is why "environmentalism is likely to provoke resistance and ideological defensiveness" (p. 10). But although system justification is an important factor in preventing people from engaging in more sustainable practices, it is most likely not the only one. People have a tendency to justify the status quo, to preserve the foundations of our socioeconomic system. But why do we cling to it so eagerly? What is really at stake?

The paper of Susanne Stoll-Kleemann, Tim O'Riordan and Carlo C. Jaeger entitled The Psychology of Denial Concerning Climate Mitigation Measures (2001) may give further clues regarding this question. Research conducted on a study group of randomly selected Swiss citizens revealed that "from the viewpoint of changing their lifestyles of material comfort and high-energy dependence, they regarded the consequences of possible behavioral shift arising from the need to meet mitigation measures as [...] daunting" (p. 107). Drawing from cognitive dissonance theory, they found that, "for the most part, denial or displacement act powerfully to maintain the gap between attitude and behaviour with regard to climate change norms" (p. 111). In their account of our refusal to acknowledge change, S. Stoll-Kleemann, T. O'Riordan 
and C. C. Jaeger e2001) finally found "the most powerful zone of denial" in "the perceived unwillingness to abandon [...] personal comfort and lifestyle-selected consumption and behaviour in the name of climate change mitigation" (p. 113).

Research in social psychology and related fields seems to indicate that people are prone to deny scientific data regarding the anthropogenic degradation of the natural world, or to deny the possibility of changing their environmentally damaging practices, because they seek to avoid the cognitive dissonance that would occur if they were to acknowledge either. This dissonance occurs because beliefs connected to lifestyle prove to be change-resistant to a considerable degree (Stoll-Kleemann et al., 2001; Lorenzoni, Nicholson-Cole, \& Whitmarsh, 2007; Tobler, Visschers \& Siegrist, 2012). Denial becomes the only way out of a cognitive impasse, a last attempt to relieve tension between conflicting cognitions. The refusal to listen to climate change experts, or to any optimistic environmentalist agenda, arises out of concern that our consumerist way of life will be deeply disturbed if we do start listening.

Being a consumer and building one's identity around objects and activities is namely not just an incidental attribute of the contemporary individual. On the contrary, consumerism seems to have penetrated the innermost recesses of our being: Chris T. Allen, Susan Fournier and Felicia Miller (2008) describe a paradigm shift in consumer research which alters the emphasis from brands as information to brands as meanings: "Consumer products were re-cast from simplifying informational vehicles to meaning-rich tools for personal and social identity construction" (p. 784). Indeed, as Belk states in his seminal paper Possessions and the Extended Self, "a key to understanding what possessions mean is recognizing that, knowingly or unknowingly, intentionally or unintentionally, we regard our possessions as parts of ourselves" (1988, p. 139). It is not only possessing objects infused with meaning that is tightly bound with personal identity, but also the mere act of acquiring these 'meaning-rich tools'. As Michaela Wänke explains, many consumer decisions are "highly identity-relevant insofar as they correspond to a larger set of values and beliefs and express important aspects of the self." (2009, p. 7)

In line with this, Irene Lorenzoni, Sophie Nicholson-Cole and Lorraine Whitmarsh (2007) report a significant perceived barrier to taking action on climate change, concerning the prospect of having to change one's lifestyle. In their qualitative studies, many participants indicated that climate change would only be achievable with great discomfort and sacrifice regarding standards of living and social image. Participants tended to be reluctant to consider changing many of their routines and habits, or to reflect on alternative options, even when these may be more individually and environmentally beneficial.

Thus, if we want to preserve our identities, we must deny the existence of anthropogenic environmental degradation. If we were to seriously admit our responsibility for natural destruction and its full consequences while still considering ourselves 'responsible citizens' and 'moral agents', we would have to abandon our consumerist lifestyles based on high energy consumption. This, however, is difficult, because our lifestyle is the basis of our identity, and consumption seems a safe and reliable embrace in the midst of our otherwise uncertain and insecure existence. "Vigorous and growing consumption is" as Albert Borgmann has it, "the 
chief indicator of a prosperous and self-confident community" (2000, p. 418). Thus any threat to the existing lifestyle must be eliminated, and because the pronouncement of human-caused environmental degradation represents such a threat, it must be silenced through denial. Because our lifestyles are harder to change than the belief that we are causing harm to the environment, it is much easier to deny the latter than to transform the former.

\section{EXPERIENTIAL EDUCATION IN ENVIRONMENTAL ETHICS AND SUSTAINABLE DEVELOPMENT EDUCATION}

"My line is that we can try to change behaviour, but it might be more effective to change the conditions that encourage our behaviours", stated David Uzzell, British environmental psychology professor, before delivering the 2010 British Academy/British Psychological Society annual lecture (Hickman, 2010). What D. Uzzell said in this interview seems to be wholly in line with what was described above: If something as important as our quest for the meaning of our existence is bound up with consumer culture, then a solution which simply advocates dropping our habits is doomed to failure. Consumerist habits cannot simply be abandoned, because the psychological state to which such a manoeuvre would push us would be highly unstable. We will continue to fight our environmental reality - or even worse: to ignore it - as long as there is nothing else on offer. Therefore, it seems only reasonable to try to modify environmentally detrimental behaviours by offering - a new bondage. That is to say: The only way to bring about environmental change is to assume new identities by engaging in activities that are less damaging for the natural world. The only feasible way to modify behaviour is to start promoting activities from which new identities and a new search for meaningful existence can be constructed. This idea seems to be in line with what I. Feygina, J. T. Jost and R. E. Goldsmith (2009) propose when they state that we should "get rid of the negative association" between system justification and environmentally protective behaviour: What we should get rid of here is the negative association, conscious or unconscious, between living rich and meaningful lives and giving up consumer habits based on the consumption of material goods.

If this new, greener bondage, i.e. new identities, built around more sustainable practices, can be seen as a remedy for environmental degradation, then the question arises how they can be brought about and how relevant activities can be promoted. The answer seems to be in the direction of experiential education. Already J. Dewey (1963) claimed "that education in order to accomplish its ends both for the individual learner and for society must be based upon experience - which is always the actual life-experience of some individual" (p. 89). Also, if moral progress is truly to be found in "re-making human selves so as to enlarge the variety of relationships which constitute those selves" (Rorty, 1999), and if experiential learning for David A. Kolb (1984) "involves the integrated functioning of the total organism - thinking, feeling, perceiving, and behaving" (p. 31), then the latter with its holistic approach clearly seems to be an appropriate candidate for ethical education based on identity formation. Also, recently Jan Oakley, Gavan P. L. Watson, Constance L. Russell, 
Amy Cutter-Mackenzie, Leesa Fawcett, Gail Kuhl, Joshua Russell, Marlon van der Waal, Traci Warkentin pointed out how "lived experiences with the more-thanhuman world form personally important narratives" (2010, p. 96) and how those experiences can shape identity, thereby supporting the idea of the fundamental and transformational role of the experience connected with the natural and animal (i.e. more-than-human) world in identity formation.

\begin{abstract}
AIMS AND METHODS
In this section we would like to outline a case study where some of the techniques of experiential education (field trip and making of the summary video) were applied at the university level to assess the practical validity of the claim that experiential education is a promising method to teach environmental ethics by increasing student environmental sensibility and overcoming of the environmental denial. The aim of the case study was thus to determine whether the scope of the (moral) dilemmas and student sensibilities increased, and whether the students were less prone to deny the detrimental impacts of human activity on the environment after the technique was implemented. The subject of the research was therefore experiential education in connection with overcoming of the environmental denial.

The pedagogical process, based on local observation of anthropogenic influences on climate change and experiential education, has been shown to be successful (e.g. Pruneau, Gravel, Bourque \& Langis, 2003; Khan et al., 2012). The process aims at improving students' conceptions of the causes of climate change, the nature of the phenomenon, signs, and consequences, as well as possibilities for mobilization. In addition, Andrew Mitchell, Bruce Oswald, Tania Voon, and Wendy Larcombe (2011) report benefits of experiential learning in other subjects, such as international law. As a consequence, students are more likely to change cognitive, affective, and behavioural components of their beliefs.
\end{abstract}

\title{
PARTICIPANTS
}

Fourteen participants took part in this case study. The estimated average age of the participants was 24 years. They were undergraduate students (mostly of Philosophy, History, and Media Studies) at the Faculty of Humanities, University of Primorska (Koper, Slovenia). The ratio between males and females was 1:6.

\section{MATERIALS AND PROCEDURE}

The case study was carried out qualitatively. The results of the preliminary study are based on structured discussion and video footage the students produced. Potential change in the environmental ethical outlook and heightened environmental sensibility in students was inferred from different types of answers $(a, b$, and c) in the discussion and video described below: observations about lifestyle, advice on more sustainable living, and statements with ethical and moral claims regarding human treatment of the environment that surfaced in the discussion 
were, when compared with answers in the short survey that was conducted before the educational technique was implemented, taken as an indicator of changed environmental outlook; they were thus taken to show heightened environmental sensibility and students' detailed engagement with environmental problematic. The presence of environmental denial in subjects was taken to be indicated by the answer "no" to the question "Do you think human activity is responsible for environmental crisis?" posed in short preliminary survey before the field trip and in structured discussion after the educational methods were implemented. Structured discussion was performed in the classroom and lasted for 30 minutes. Answers were tape-recorded and transcripts of the discussion were made. Further on, content analysis of students' answers was administered.

An outdoor field trip took place within the Ethics and the Knowledge-Based Society course in the academic year 2010-2011. When teaching environmental ethics, we decided to arrange a field trip for students to a nearby landfill. Prior to the trip, the degree of environmental denial present in faculty students was measured by a short survey. The results showed that one third of the students ( 5 students) were reluctant to accept the fact that human actions are a considerable factor in environmental degradation.

The excursion took around 90 minutes and was guided by an employee who showed the amount of waste collected over the past 40 years and explained the possibilities offered by recycling methods. The guide also explained what dangerous waste is and how it is managed, while also explaining the modus operandi of the landfill.

After the excursion, students participated in a discussion intended to check potential change in students' outlooks regarding environmental denial. The group discussion took place in the classroom, moderated by the teacher. The questions posed by the teacher ranged from technical questions, addressing practicalities of waste management, to ethical questions tackling the issue of over-consumption. Students' answers were written down and later compared to the views presented on students' video: for their assignment a group of 4 students produced their own video with a TV crew about pollution and waste management that was later broadcast on national TV. The topics addressed by the students dealt mainly with ethical issues connected with over-consumption (the impact of pollution on animal populations, specifically on seabirds in the video) and advice about sustainable living (sorting and recycling household waste, as well as (re)using plastic shopping bags), indicating students' change with respect to environmental denial.

\section{RESULTS}

The aim of the field trip was to engage students in pro-environmental behaviour (producing an environmental education video and becoming environmental educators themselves, which was supposed to be a strong formative practice) in order to reshape their ethical identities and lessen the degree of environmental denial present in this student population. This aim was achieved, if judged by subsequent structured discussion in class and the video the students produced. According to our results, 
drawn from students' answers in structured discussion, no students still denied our impact on the environment after the excursion took place. This can be seen in the answers to the question "Do you think human activity is responsible for environmental crisis?" posed before (when 9 students answered "yes" and 5 "no") and after the educational techniques were implemented (when all subjects answered "yes"). That the environmental outlook change in students was more substantial than just switching from "no" to "yes" answers when asked about human impact on the environment can be seen from other answers (described below) to the questions posed in the discussion which show raised concerns about human way of unsustainable living in comparison to the views expressed in the short survey before the field trip took place. In the results there was no significant difference in outlooks of male and female students (but since the number of male students was comparatively low ( 2 students), the results do not afford any further gender-specific generalization).

The issues addressed by students in the discussion and video range from (a) observations about our lifestyles to (b) practical advice on sustainable living, to (c) ethical questions dealing with human attitudes towards the natural world. "One of the biggest problems are plastic shopping bags," the students observed (a) in the video, "because a lot of them end up in nature. They are used for only 20 minutes, but it takes up to 1000 years for them to disintegrate." "Production of aluminum cans is very harmful to the environment because it is highly energy inefficient," is another observational statement (a) they produced, based on their own research. One of the pieces of advice (b) the students wanted to spread dealt with recycling and sorting waste: "Ethics are reflected in society through waste sorting sites ... Have you ever asked yourselves what happens to a product after you discard it and it becomes waste? ... With small steps that will become routine, we can save a number of lives and prolong the life of the Earth." When it comes to ethics, the students did a great job presenting and reflecting on Leopold's Land Ethic. When thinking about environmental change, they produced the following statement (c) in the video: "Only a feeling of being a part of the environment will trigger the desire to start dealing with its destiny". Numerous other (a), (b), and (c) answers and statements were produced by the students during the structured discussion and in the video, but the following one from the video was exceptional in the sense that it immediately drew the authors' attention to the students' change with respect to environmental denial after the trip: "All of the actions we perform have implications for the environment". This sentence, combined with their exposition of Leopold's ethics in class, helped us conclude that the experiential education experiment yielded positive results in connection with students' environmental outlook change. At least on the level of outlook, students now fully acknowledged our impact on the environment and there were no students who still denied the detrimental anthropogenic impact on the natural world (compared to one third of the population that did so before the excursion took place).

\section{DISCUSSION}

According to I. Lorenzoni, S. Nicholson-Cole and L. Whitmarsh (2007), widespread awareness and concern about climate change exists. However, this often 
does not translate into personal engagement in terms of cognitive, affective, and behavioural changes. Instead, people imagine climate change as a distant reality of people in other locations and time periods. Even the majority of victims that have experienced climate change catastrophes tended to deny global consequences for the environment and reported difficulty in recognising the consequences of their current lifestyle for future climate change (Lorenzoni, et al., 2007). In light of these findings, what is needed to trigger environmental change is an environmental education that will be able to result in personal engagement and lessen the impact of environmental denial. In this paper we suggest experiential education might be the right answer to this challenge.

However, it has to be acknowledged that not all groups exhibit unsustainable behaviour in the same way, or to the same degree: consider, for instance, vegans, indigenous populations, as well as some developing nations. The issue of having an unsustainable ecological footprint is predominantly problematic in the developed Western world with its (sub)urban populations. Indeed, it seems that the problem of unsustainability is bound up with Western consumerism as such, and therefore the idea of building new identities around different forms of consumerism, as suggested here, might strike one as odd. Wouldn't it be better to do away with consumerism entirely? Even though this seems to be a more holistic solution than the one advocated here, it does not sound very plausible if we consider how thoroughly consumerism permeates our culture in the sense that it plays an important role in our identity-shaping, as shown above. Simply abandoning consumerism would trigger feelings of anxiety in individuals, and avoidance of these feelings is precisely the reason why they are prone to deny phenomena that might signal lifestyle changes in the first place. Furthermore, because the environment is being degraded at an extraordinarily fast rate, waiting for perfect answers to problems might make us miss the chance to make smaller, but none the less important, steps.

Another theoretically pressing issue with regard to the solution here proposed is the fact that responsibility for environmental degradation seems to be put on the shoulders of the individual through his or her process of identity-building, when it is actually the specific form of the Western social structure that presses individuals into the consumerist mould. This move seems to ignore collective responsibility for environmental degradation, and the role governments, multinationals, and international decision-making bodies should play in the environmental story. Here we should make a clear distinction between the process of the individual's identity-formation and the factors that influence this formation: while the process occurs to an individual, factors that influence this process are often out of the individual's reach. This is also the reason why the proposed form of experiential education presented in this paper is not primarily oriented towards individuals but is supposed to be picked up and enforced by educational policies on a wider social scale. The fact that these policies must pay close attention to the process of an individual's identityformation should not make us think that the onus should exclusively, or predominantly, be on individuals - thus neglecting institutional and social responsibility.

Some of the methodological limitations of this study should be mentioned at the end. First of all, the design of the study and the numbers do not allow gen- 
eralizations regarding the phenomena studied. Secondly, the case study lacks information about the consequences of the landfill trip. Did students change their attitudes and their behaviour to more environmentally sound ones? For future research a longitudinal approach is planned in order to analyse environmentally relevant attitude change. Thirdly, a specific student population participated in this study. This refers not only to a specific age group, but also to their more or less humanistic orientation, which is a biased sampling of the (student) population. In the future, we plan to expand our research endeavours to experiential learning by other target groups (e.g. primary school children, teenagers, seniors) by handling other climate change phenomena, involving, for example, animal welfare education, public transport usage, etc. Furthermore, special research efforts will be made to learn more about environmental denial and how to overcome it, including more detailed investigation of cognitive, affective, and behavioural components of students' beliefs. Up to the present, not much is known about the personal characteristics that help to support or mitigate it.

\section{CONCLUSIONS}

Findings of the present study show that the implementation of experiential education technique (field trip, "video making") yields positive results in connection with overcoming of environmental denial, i.e. the denial that anthropogenic factors contribute to considerable environmental degradation. Environmental denial, a belief caused by mechanisms closely related to identity formation process, was shown to be successfully overcome with educational practices that focused on changing environmental outlooks in subjects by employing field trip and video making as educational techniques.

However, since the present research represents only a case study, based on limited number of participants (14), the obtained results cannot be widely generalized. Nonetheless, the results do open up promising avenues for further research. The perceived success of experiential education exposes a deficiency of more traditional versions of sustainable development education which do not take into account the nature of the phenomenon of environmental denial and its role in environmental education, and which are often based on classroom teaching as well as negative motivation of students (anticipation or fear of a negative outcome resulting from environmental inaction).

\section{REFERENCES}

Allen, C. T., Fournier, S. \& Miller, F. (2008). Brands and Their Meaning Makers. In: C. Haugtvedt, P. M. Herr \& F. Kardes (Eds.), Handbook of Consumer Psychology (pp. 781-814). New York: Taylor \& Francis.

Belk, R. W. (1988). Possessions and The Extended Self. The Journal of Consumer Research 15 (2), 139-168. Borgmann, A. (2000). The Moral Complexion of Consumption. The Journal of Consumer Research 26 (4), 418-422.

Dewey, J. (1963). Experience and Education. New York: Macmillan.

Diethelm, P., McKee, M. (2009). Denialism: what is it and how should scientists respond? European Journal of Public Health 19 (1), 2-4. 
Feygina, I., Jost, J. T. \& Goldsmith, R. E. (2009). System Justification, the Denial of Global Warming, and the Possibility of "System-Sanctioned Change". Personality and Social Psychology Bulletin XX(X), $1-13$.

Hickman, L. (2010). What psychology can teach us about our response to climate change. The Guardian Environment Blog. Retrieved September 23, 2010,from http://www.guardian.co.uk/ environment/blog/2010/sep/23/climate-change-psychology-response-scepticism

Khan, A. S., Ramachandran, A., Usha, N., Aram, I. A. \& Selvam, M. (2012). Raising Sea and Mangroves A Case Study on Stakeholders, Engagement in Climate Change Communication and Non-Formal Education. International Journal of Sustainable Development \& World Ecology 19 (4), 330-338.

Kolb, D. A. (1984). Experiential Learning: Experience as the Source of Learning and Development. Englewood Cliffs, NJ: Prentice Hall.

Leopold, A. (1949). Land Ethic. In A. Leopold (1949), A Sand County Almanac (pp. 201-226). Oxford: Oxford University Press.

Lorenzoni, I., Nicholson-Cole, S. \& Whitmarsh L. (2007). Barriers Perceived to Engaging with Climate Change Among the UK Public and their Policy Implications. Global Environmental Change 17, 445-459.

Newell, B. R. \& Pitman, A. J. (2010). The Psychology of Global Warming: Improving the Fit between the Science and the Message. American Meteorological Society Bulletin, 2010, 1003-1014.

Mitchell, A., Oswald, B., Voon, T. \& Larcombe W. (2008). Education in the Field: A Case Study of Experiential Learning in International Law. Legal Educator Review 21 (1-2), 69-95.

Oakley, J., Watson, G. P. L., Russell, C. L., Cutter-Mackenzie, A., Fawcett, L., Kuhl, G., Russell, J., van der Waal, M. \& Warkentin, T. (2010). Animal Encounters in Environmental Education Research: Responding to the 'Question of Animal'. Canadian Journal of Environmental Education 15, 86-102.

Pruneau, D., Gravel, H., Bourque, W. \& Langis, J. (2003). Experimentation with a Socio-Constructivist Process for Climate Change Education. Environmental Education Research 9 (4), 429-446.

Rorty, R. (1998). Human Rights, Rationality, and Sentimentality. In R. Rorty (1998), Truth and Progress (Philosophical Papers, vol. 3) (pp. 167-185). Cambridge: Cambridge University Press.

Rorty, R. (1999). Philosophy and Social Hope. London: Penguin.

Stoll-Kleemann, S., O'Riordan, T. \& Jaeger, C. C. (2001). The psychology of denial concerning climate mitigation measures: evidence from a Swiss focus group. Global Environmental Change 11 (2001), 107-117.

Tobler, C., Visschers, V. H. M., \& Siegrist, M. (2012). Addressing Climate Change: Determinants of Consumers' Willingness to Act and to Support Policy Measures. Journal of Environmental Psycho$\log 32$ (3), 197-207.

Wänke, M. (2009). What's Social About Consumer Behavior? In: M. Wänke (Ed.), Social Psychology of Consumer Behavior (pp. 3-18). New York: Taylor \& Francis. 